\title{
HARMONICS IN POWER SYSTEMS AND FILTER APPLICATIONS
}

\author{
Berkay SABUNCU1, Ali Bekir YILDIZ1* \\ ${ }^{1}$ Kocaeli University, Department of Electrical Engineering, Kocaeli, Turkey
}

Received: May 15, 2019; Accepted: June 21, 2019; Published: October 01, 2019

\begin{abstract}
With the advancing technology, loads in the power systems have been varied in the consideration of their features. These loads are always expected to be linear. However, with the effect of developing semiconductor technology, it has been observed an increase concerning nonlinear loads in the system. Current and voltage characteristics of nonlinear loads show nonlinear behavior. Nonlinear loads cause harmonic currents and voltages in the power system. Major loads causing harmonics are power electronic components, transformers, uninterruptible power supplies (UPS), converters and high-power induction motors. Harmonics cause additional energy losses in the system, heat effect and damage to the insulation of electrical components. Because of these reasons, it is essential to reduce or eliminate harmonics after the formation or to block them before the formation. Harmonic filtering method by use of passive or active filter is one of the most important harmonics eliminating ways. In this study, firstly, it is given basic information about harmonics, their effects on energy system and harmonic filtering methods. Then, a sample system model is established and simulated through MATLAB/SIMULINK program and the effect of passive filters is examined.
\end{abstract}

Keywords: Harmonic analysis, Filter circuits, Resonance circuits

*Corresponding author: Kocaeli University, Department of Electrical Engineering, Kocaeli, Turkey

E mail: abyildiz@kocaeli.edu.tr (A.B. YILDIZ)

Ali Bekir YILDIZ (iD) https://orcid.org/0000-0003-4043-7859

Berkay SABUNCU (iD) https://orcid.org/0000-0003-4043-7859

Cite as: Yildiz AB, Sabuncu B. 2019. Harmonics in power systems and filter applications. BSJ Eng Sci, 2(4): 117-122.

\section{Introduction}

Quality of electrical energy in an electrical transmission system is defined by the continuity of electricity, the variation of voltage and frequency within limits and waveform uniformity. In order for electrical power systems to operate reliably, a number of factors must be considered in the design and operation phase. One of these factors is the harmonics produced by nonlinear elements. Nonlinear elements in electrical power systems cause serious harmonic pollution in transmission and distribution systems, and it affects negatively the energy quality delivered to consumers (Kocatepe et al., 2003; İlaslaner, 2006; Sucu, 1993; Efe, 2015).

In electrical energy systems, the waveforms of magnitudes such as current and voltage should have a sinusoidal change in fundamental frequency. For this purpose, the system must be fed by sinusoidal sources and loaded with linear loads. The current in the linear element of a system is compatible with the voltage. However, nonlinear loads such as transducers, arc furnaces, and power electronics components connected to power systems can cause current and voltage magnitudes in the system to be non-sinusoidal, ie harmonic distortion. Nonlinear loads, even at low values, still distort the 
voltage waveform. Figure 1 shows typical current voltage characteristics of linear loads and nonlinear loads.
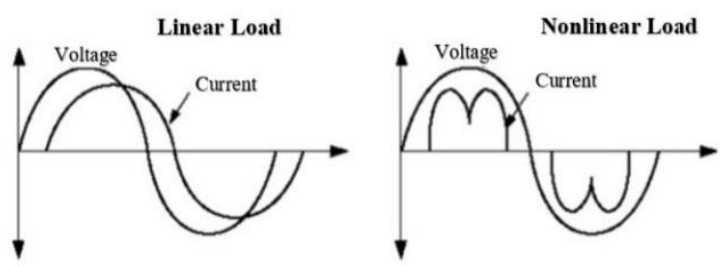

Figure 1. Current - voltage characteristics of linear loads and nonlinear loads.

When nonlinear elements and/or non-sinusoidal sources are available in the system, it is known that the waveforms of current and voltage in the system are distorted. These waveforms can be analyzed by applying the analysis method known as Fourier analysis. J. Fourier, a French mathematician; showed that a non-sinusoidal periodic wave is composed by the sum of sinusoidal waves with different amplitudes and frequencies. So; he reported that non-sinusoidal periodic waves can be divided into sinusoidal waves with different amplitudes and frequencies. The obtainment of the Fourier series is also defined as wave analysis or harmonic analysis.

When the periodic functions are expanded to the Fourier series, the first term is written as a constant, and the other terms are written as a series of sine and cosine with different amplitudes and frequencies.

$f(t)=A_{0}+\sum_{n=1}^{\infty}\left(A_{n} \cos n t+B_{n} \sin n t\right)$

Fourier coefficients in the series are found by the following formulas;

$A_{0}=\frac{1}{T} \int_{0}^{T} f(w t) d w t$

$A_{n}=\frac{2}{T} \int_{0}^{T} f(w t) \cos (n w t) d w t$

$B_{n}=\frac{2}{T} \int_{0}^{T} f(w t) \sin (n w t) d w t$

\section{Resonance Circuits}

In an electric circuit, the resonance occurs in case that inductive reactance and capacitive reactance is equal. In some circuits, the working principle of the devices is based on the formation of resonance. Filter circuits are given an example to these kinds of circuits. Filter circuits are generally be used to protect power systems from harmonics. Two types of resonance occur in electrical circuits (Yildiz, 2016).

Series resonance: In this case (Figure 2), the circuit impedance is min. and equal to resistance. The resonance current with high amplitude will flow in the circuit.

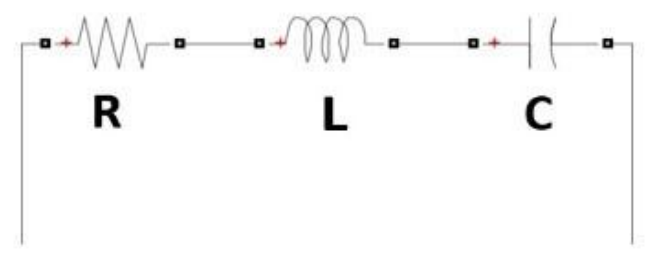

Figure 2. Series resonance circuit.

Resonance frequency,

$f_{r}=\frac{1}{2 \pi \sqrt{L C}}$

Figure 3 shows impedance-current characteristic in series resonant circuit.

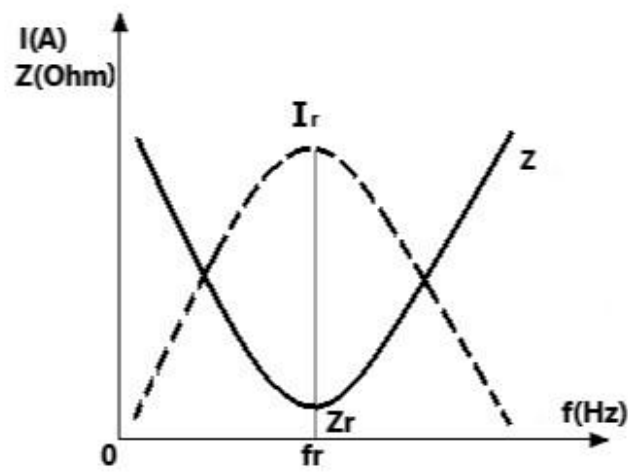

Figure 3. Impedance-current characteristic in series resonant circuit.

Parallel resonance: In this case (Figure 4), the circuit admittance is min. and equal to conductance. The resonance current with low amplitude will flow in the circuit.

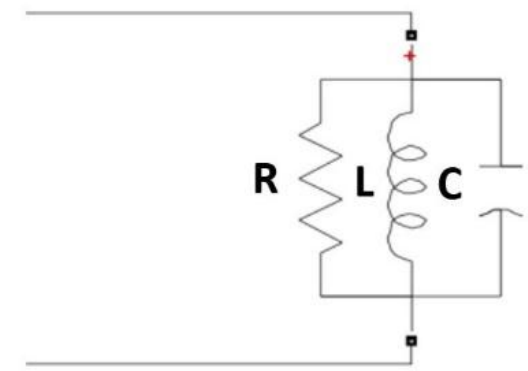

Figure 4. Parallel resonance circuit.

Resonance frequency,

$f_{r}=\frac{1}{2 \pi \sqrt{L C}}$

Figure 5 shows impedance-current characteristic in parallel resonant circuit. 


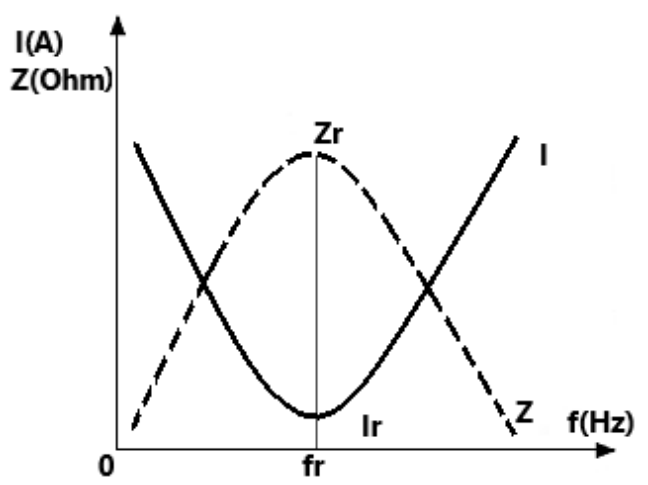

Figure 5. Impedance-current characteristic in parallel resonance circuit.

Resonance Analysis of Series LC Circuit: In order to show resonance effect, the circuit in Figure 6 is considered as an example.

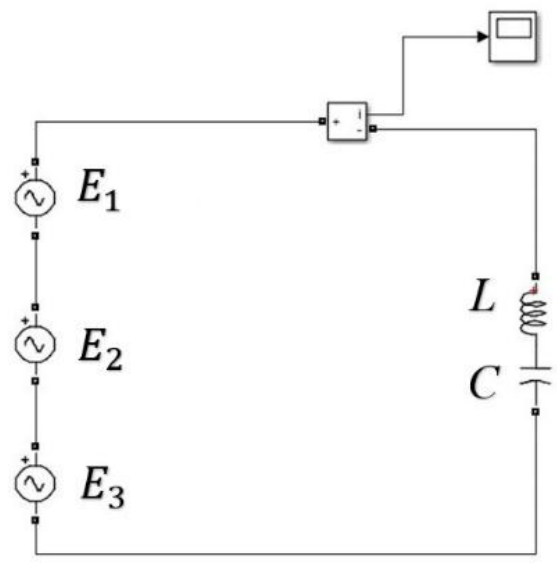

Figure 6. Series LC circuit analysis.

The sources in Figure 6 are, $E_{1}=10 \sin (1000 t)$, $\mathrm{E}_{2}=5 \sin (1250 t), \mathrm{E}_{3}=2 \sin (3000 t)$, and $\mathrm{L}=60 \mathrm{mH}, \mathrm{C}=10 \mu \mathrm{F}$.

The resonance frequency of the circuit is calculated as $205.46 \mathrm{~Hz}$ according to Equation 5). So, the angular frequency is $1290 \mathrm{rd} / \mathrm{s}$. Since the frequency of each source is different, the source effects are examined separately in the circuit analysis (Superposition theorem).

$i_{1}=\frac{10 \cdot \sin (1000 t)}{Z_{L C}}=0,25 \cdot \sin \left(1000 t+90^{\circ}\right)$

$i_{2}=\frac{5 \cdot \sin (1250 t)}{Z_{L C}}=1 \sin \left(1250 t+90^{\circ}\right)$

$i_{3}=\frac{2 \cdot \sin (3000 t)}{Z_{L C}}=0,013 \cdot \sin \left(3000 t-90^{\circ}\right)$

Figure 7 shows every current component and the total current component concerning calculations. The most effective source is the source whose frequency is the nearest one to resonance frequency. In this example, $\mathrm{E}_{2}$ source has the nearest frequency to resonance frequency. So, this source has the biggest effect on the total current. This feature of the resonant circuits is used in design of harmonic filtering circuits.

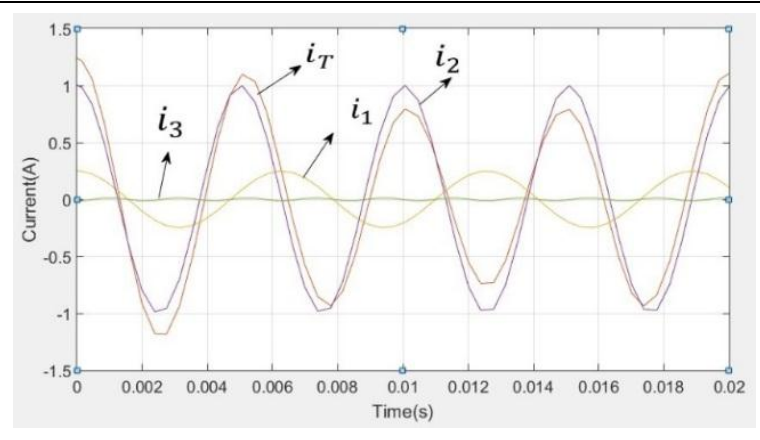

Figure 7. Source currents and total current.

\section{Filter Circuits}

The purpose of harmonic filters is to reduce the harmonic levels at different frequencies or to clear the harmonics (Jiangzi, 2015; Motta and Faundes, 2016; Abdelkader, 2008; Abbas, 2000; Yang et al., 2000). Design is generally made for the most effective harmonic components. For a low effect harmonic component, an attenuation filter circuit can be considered. There are two types of harmonic filter circuits: Active and passive filters. In this study, passive filter circuits are examined.

Passive Filters: Passive filters contain basically passive elements like capacitors and inductors. Passive filters contain series or parallel connected capacitors and inductors between the source and the load, which eliminate components outside the fundamental frequency. In some cases, resistors can be also added. The purpose of filter design is to determine the $\mathrm{L}$ and $\mathrm{C}$ values that will resonate in the harmonic component frequency to be eliminated. A separate filter component is required to resonate each harmonic component. Quality factor $\mathrm{Q}$ determines the setting effectiveness. According to the quality factor, the filters are separated as high pass filter or low pass filter.

Series Filters: The series filters are connected in series between the harmonic source and electric network, and show a high impedance to the harmonic flow (Figure 8). Therefore, there is a low impedance at the frequency where the serial filters are set. Since the serial filter is set to a specific frequency, only it reacts a low impedance at the fundamental frequency, a high impedance at the other harmonic frequencies. The major disadvantages of the serial filters are that they carry the full load current and must be isolated according to the line voltage. However, they do not cause resonance.

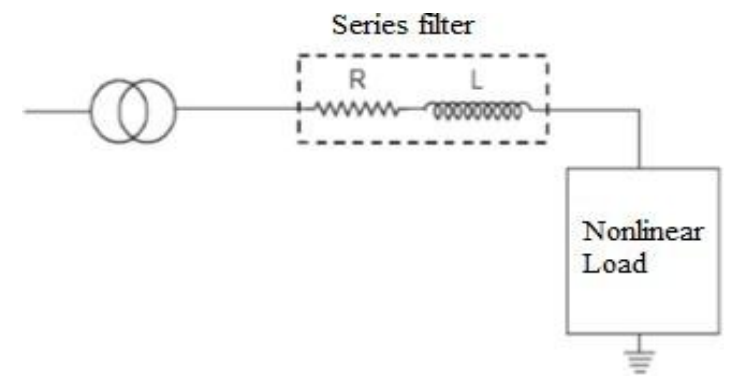

Figure 8. Series harmonic filter. 
Parallel Filters: The purpose of parallel filters provides a different path to harmonic components. The harmonic current components can be transferred to the ground by means of a low impedance parallel path. So, they can be prevented from circulating in the system. They are connected in parallel between the harmonic source and the network (Figure 9). It is aimed that harmonic currents pass via the filter by means of a low shunt impedance.

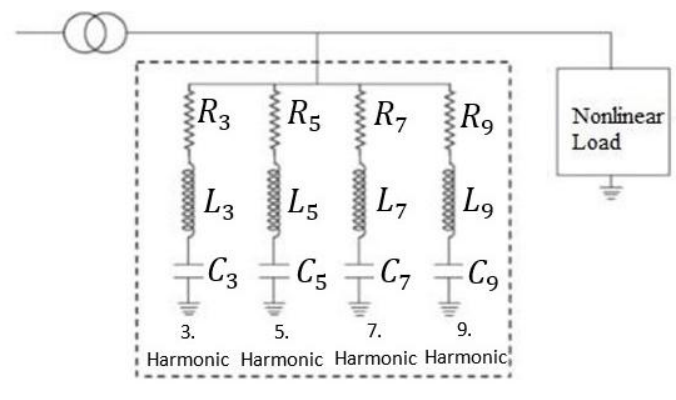

Figure 9. Parallel harmonic filters.

Single tuned filters: They consist of a series RLC circuits (Figure 10). Single-tuned filters create a low impedance or short circuit to suppress the harmonic currents at the set frequency.
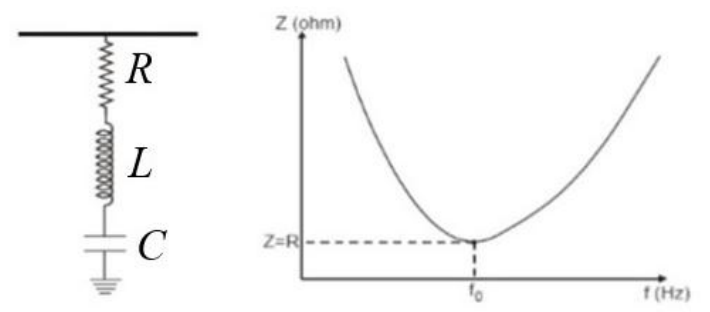

Figure 10. Frequency-impedance change of Single-tuned filter.

Double tuned filters: They are set to two different frequencies, and they provide low impedance at these frequencies (Figure 11). So, they allow the harmonic components to be filtered at tuned frequencies. The most important feature has a low power loss at the fundamental frequency.

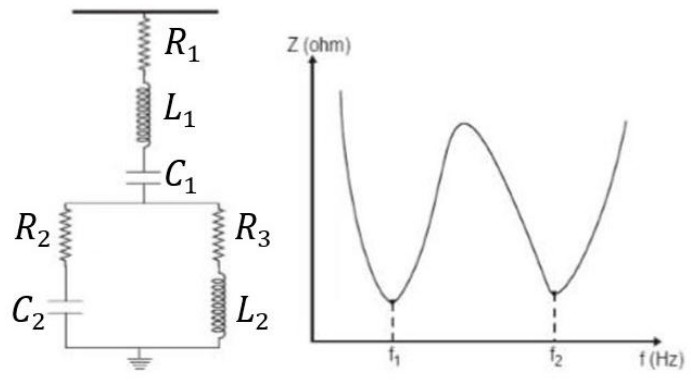

Figure 11. Frequency-impedance change of Dual-tuned filter.

Damped filters: They are used to filter high-order harmonics (i.e.,17th and above). Therefore, they are called high pass filters. Accordingly, these filters show high impedance to high frequencies and low impedance to low frequencies (Figure 12).

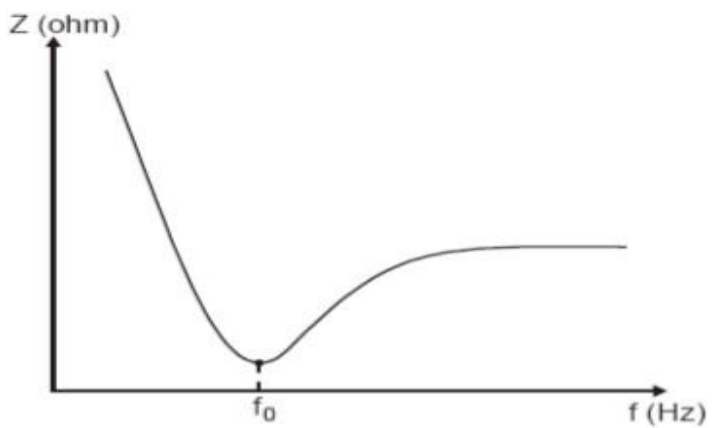

Figure 12. Frequency-impedance change of Damped filter.

\section{Simulation Results}

In order to explain harmonic effects, the system in Figure 13 is simulated. In the system, the single-phase RL load is affected by the harmonic currents at the $3^{\text {th }}, 5^{\text {th }}$ and $7^{\text {th }}$ order due to the nonlinear loads. Harmonic sources (nonlinear loads) are modeled by current sources. Figure 14 shows the source current without filter circuits. The filter circuits are included into system, respectively. Figure 15 shows the source current after the 3th order filter is connected, Figure 16 shows the source current after the $3^{\text {th }}$ and the $5^{\text {th }}$ order filters are connected, Figure 17 shows the source current after all filters are connected.

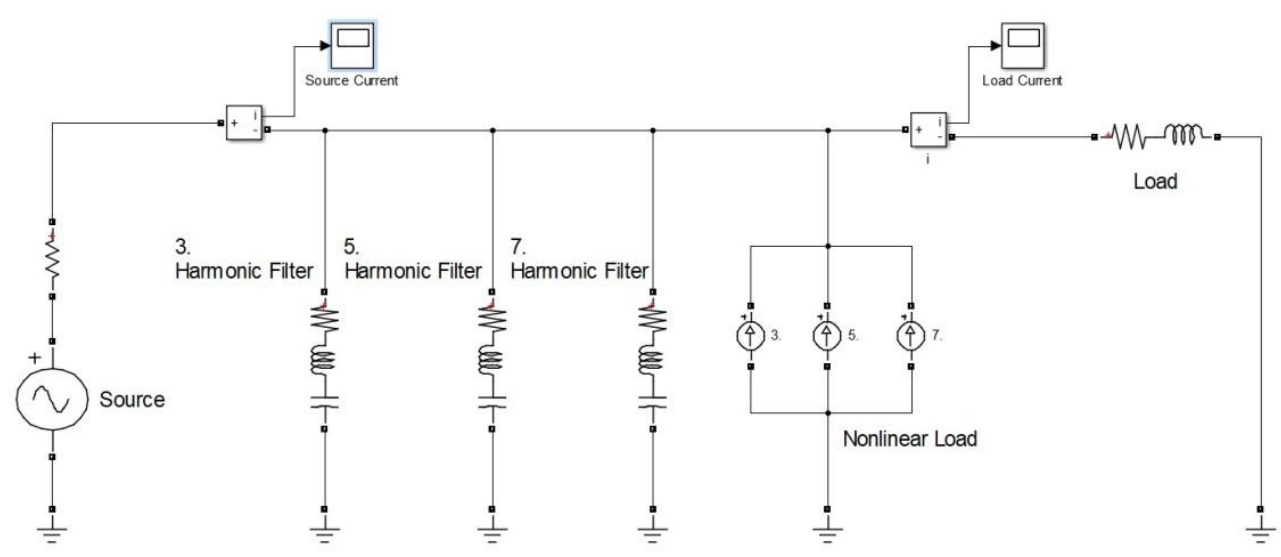

Figure 13. Harmonic filter simulation in a single-phase system 


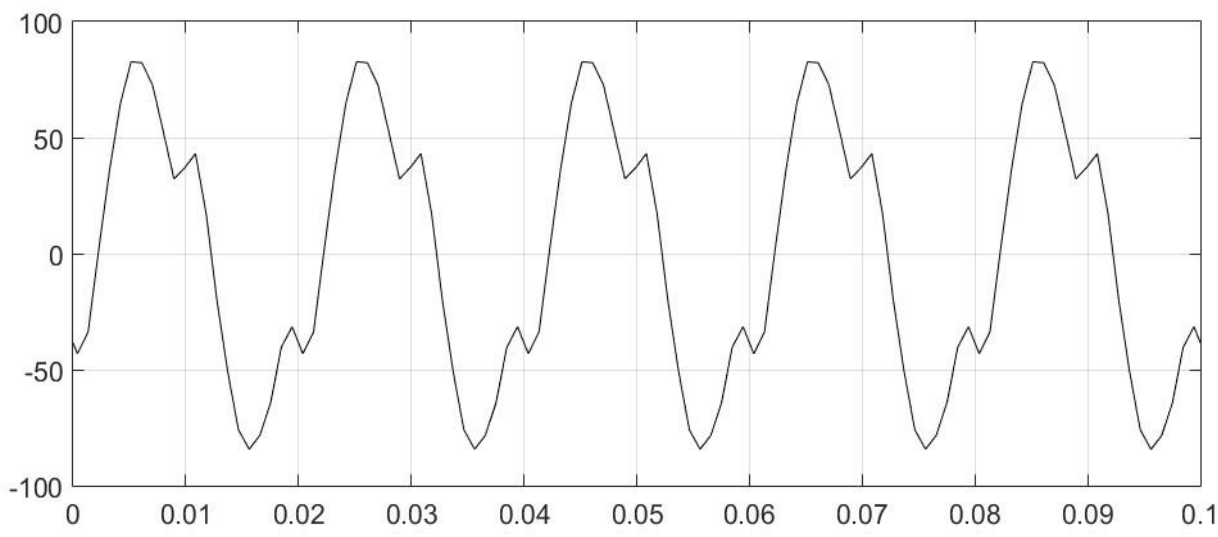

Figure 14. Source current without filter circuits.

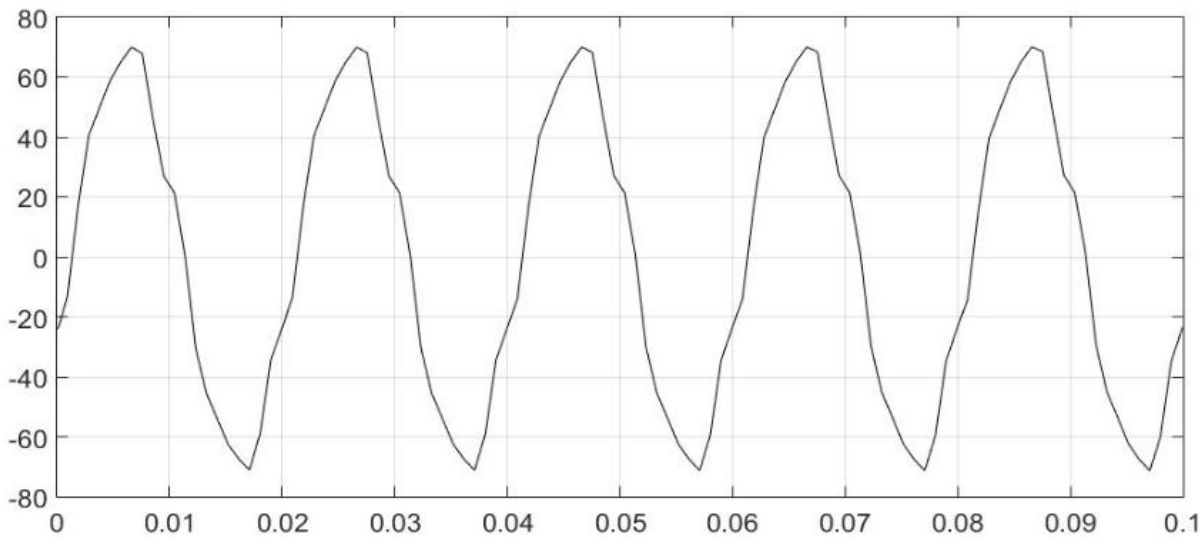

Figure 15. Source current with $3^{\text {th }}$ order filter.

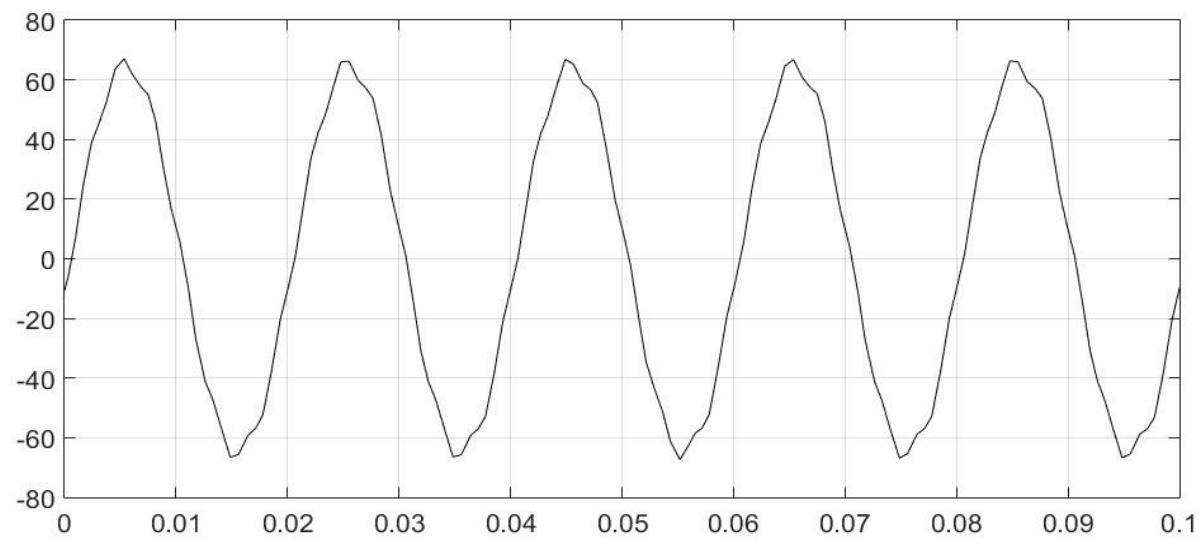

Figure 16. Source current with $3^{\text {th }}$ and $5^{\text {th }}$ order filters.

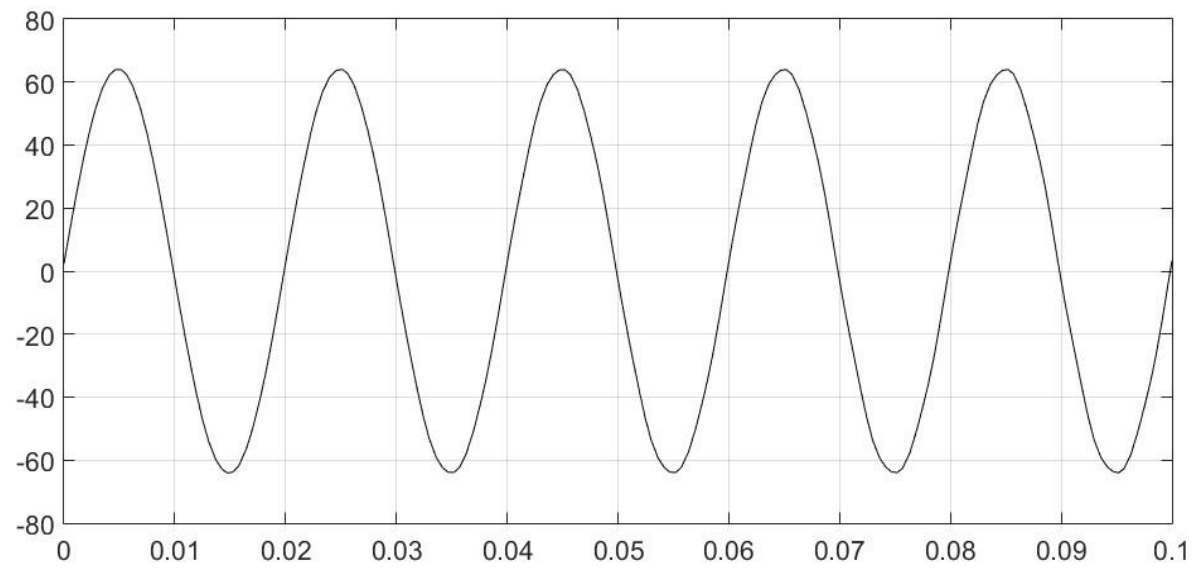

Figure 17. Source current with all filters. 


\section{Conclusion}

In electrical energy systems, it is desired that the frequency is constant, voltage and current are sinusoidal. Only in this way, quality energy can be provided to consumers. The increase in the nonlinear loads entering the system, day by day, distorts the wave shapes of the voltages and currents. Therefore, harmonics occurred in the system bring with them many problems.

The reduction, mitigation or elimination of harmonics provides a great benefit for energy systems. However, it seems that it is impossible in today's conditions. Therefore, the effects of harmonics must be reduced or even completely eliminated. There are two methods to realize this: The first is to design a device that will not produce any harmonics or will produce low level harmonics, the other one is to remove or reduce harmonics from the system by harmonic filters.

In this study, the definitions, effects and mathematical analysis of the harmonics, which are very important for all sectors using electrical energy, are examined. The filters, which are one of the methods used for elimination of harmonics, are discussed. The simulation results show the efficiency of filters in reducing harmonics.

\section{Conflict of interest}

The authors declare that there is no conflict of interest.

\section{References}

Kocatepe C, Uzunoğlu M, Yumurtacl R. 2003. Harmonics in electrical installations. Birsen Press, Istanbul.

İlaslaner I. 2006. Harmonics and filtering in power systems. Master Thesis, Gazi University, Ankara.

Sucu M. 1993. Computer aided modeling and simulation of harmonics in electric energy systems. Master Thesis, İstanbul Unversity.

Efe SB. 2015. Harmonic filter application for an industrial installation. 13th Int Conf on Engineering of Modern Electric Systems (EMES), 1-4.

Yildiz AB. 2016. Electric circuits, Part II. Volga Press, Kocaeli.

Jiangzi ML. 2005. Application of adaptive filtering in harmonic analysis and detection. IEEE PES Transmission \& Distribution Conf Exp Asia and Pacific, 1-4.

Motta L, Faundes N. 2016. Active/passive harmonic filters: Applications, challenges \& trends. 17th Int Conf on Harmonic and Quality of Power (ICHQP), 657-662.

Abdelqader RO. 2008. Method to model active harmonic filter in harmonic simulation packages. 13th Int Conf on harmonics and quality of power, 1-6.

Abbas MH. 2000. Total harmonic distortion analysis simulation. Int Conf on Power System Technology. Proceedings, 16311634.

Yang JZ, Yu CS, Liu CW. 2000. A new method for power signal harmonic analysis. IEEE Transactions on Power Delivery, 20(2): 1235-1239. 